\section{Aromaticity of soil fulvic acid}

FARMER and Pisaniello ${ }^{1}$ claim that: (1) aliphatic and aromatic oxidation products of the podzol Bh fulvic acid, especially after premethylation with diazomethane, are mainly artefacts or contaminants; and (2) the formation of these oxidation products cannot be reconciled with the ${ }^{13} \mathrm{C}$ NMR spectrum of the fulvic acid.

I have the following comments: (1) Benzenecarboxylic, phenolic and aliphatic carboxylic acids are not only the major oxidation products of the alkaline $\mathrm{KMnO}_{4}$ oxidation of unmethylated and methylated fulvic acid ${ }^{2}$, but also result from the oxidation of unmethylated fulvic acid with alkaline $\mathrm{CuO}$ (ref. 3) and alkaline $\mathrm{H}_{2} \mathrm{O}_{2}$ (ref.4) as well as $\mathrm{HNO}_{3}$ (ref. 5) and $\mathrm{CH}_{3} \mathrm{CO}_{2} \mathrm{OH}$ (ref. 6). Thus, diazomethane has nothing to do with the types of products resulting from the oxidation of the fulvic acid.

(2) Both solid-state ${ }^{7}$ and liquid-state (refs 8,9 ) ${ }^{13} \mathrm{C}$-NMR spectra of fulvic acid show signals near 20 and 30 p.p.m., indicative of the presence of terminal $\mathrm{CH}_{3}$ and $\left(\mathrm{CH}_{2}\right)_{n}$ in alkyl chains. Other resonances are detected between 50 and 85 p.p.m., arising from amino acids and carbohydrates. Major signals near 130 p.p.m. indicate the presence of aromatic carbons not substituted by $\mathrm{O}$ or $\mathrm{N}$. But in the liquid-state ${ }^{13} \mathrm{C}$-NMR spectrum of the methylated fulvic acid ${ }^{8}$, now soluble in $\mathrm{CDCl}_{3}$, the broad band near 130 p.p.m. is resolved into four sharp signals, clearly indicating improved resolution. The comments of Farmer and Pisaniello on this point are irrelevant because they erroneously assumed that this spectrum was run in base instead of $\mathrm{CDCl}_{3}$. Other strong signals in the ${ }^{13} \mathrm{C}$-NMR spectrum of fulvic acid appear near 180 p.p.m., due to carbon in $\mathrm{CO}_{2} \mathrm{H}$ groups. While some humic sub-stances show signals between 150 and 160 p.p.m., others do not. It is possible that because of substitution effects, the chemical shift due to phenolic carbon is moved downfield so that signals arising from phenolic carbon and carbon of $\mathrm{CO}_{2} \mathrm{H}$ groups overlap. It is noteworthy that after methylation of the fulvic acid the presence of phenolic carbon is indicated by a sharp signal at 56.3 p.p.m. Thus, contrary to the claims of Farmer and Pisaniello $^{1}$, the structural information on fulvic acid provided by ${ }^{13} \mathrm{C}$-NMR agrees with that indicated by chemical degradation.

Dialkyl phthalates are the only plasticizers that have so far been detected in oxidation products of fulvic acid ${ }^{2}$. The oxidation of dialkyl phthalates would be expected to yield benzenedicarboxylic acids. But how can dialkyl phthalates be oxidized to benzenetri-, tetra-, penta- and hexacarboxylic acids and phenolic acids?
Therefore, it is highly unlikely that significant amounts of oxidation products arise from contaminants. Another important indicator of aromatic fulvic acid components is the relatively high content of free radicals ${ }^{4}$ that have the spectroscopic characteristics of semi-quinones. I conclude from the above that aromatic structures are significant constituents of fulvic acid. The question of whether or to what extent hydroxyl-substituted unsaturated aliphatic carboxylic acids are present in fulvic acid, awaits the isolation of significant amounts of such structures, which, so far, nobody has been able to do.

\section{SCHNITZER}

Chemistry and Biology Research Institute, Agriculture Canada,

Ottawa, Ontario, Canada K1A 0C6

1. Farmer, V. C. \& Pisaniello, D. L. Nature 313, 474-475 (1985).

2. Schnitzer, M. \& Khan, S. U. Humic Substances in the Environment (Dekker, New York, 1972).

3. Neyroud, J. A. \& Schnitzer, M. Proc. Soil Sci. Soc. Am. 38, $90 \%-913(1974)$

4. Schnitzer, M. in Soil Organic Matter (eds Schnitzer, M. \& Khan, S. U.) 1-64 (Elsevier, Amsterdam, 1978)

5. Hansen, E. H. \& Schnitzer, M. Proc. Soil Sci. Soc. Am. 31, 79-85 (1967).

6. Schnitzer, M. \& Skinner, S. I. M. Can. J. Chem. 52, $1072-$ 1080 (1974).

7. Hatcher, P. G., Schnitzer, M., Dennis, L. W. \& Maciel, C. E. J. Soil Sci. Soc. Am. 45, 1089-1094 (1981).

8. Preston, C. M. \& Schnitzer, M. J. Soil Sci. Soc. Am. 48, 305-311 (1984).

9. Preston, C. M. \& Blackwell, B. Soil Sci. 139, 89-95 (1985).

FARMER REPLIES-Preston and Schnitzer $^{1}$ suggested that the four sharp aromatic carbon signals that they observed in the ${ }^{13} \mathrm{C}$-NMR spectrum of methylated fulvic acid might arise from benzene polycarboxylic esters, and supposed that the parent acids would not be detectable in ${ }^{13} \mathrm{C}$-NMR spectra of fulvic acid dissolved in alkali. We found ${ }^{2}$ that such acids were readily detectable as sharp signals when added to an NaOD solution of fulvic acid: our comments are therefore entirely relevant, as they negate Preston and Schnitzer's hypothesis ${ }^{1}$, and establish, conclusively, that simple benzene polycarboxylic acids are not even a minor component of fulvic acid. The four sharp signals observed in the methylated fulvic acid can arise from little more than four different types of benzenoid carbon. They are therefore unlikely to be associated with benzenoid carbons of the diverse types indicated by the multiple aromatic degradation products of fulvic acid, reported by Schnitzer and co-workers. The four bands are more likely to arise from a contaminant.

The references cited above by Schnitzer illustrate that reports of high yields of benzene and hydroxybenzene polycarboxylic acids in the oxidation products of humic and fulvic acids originate almost entirely from his laboratories. Consider- ing, for example, only the non-phenolic benzene polycarboxylic acids, Schnitzer and co-workers have reported yields mostly in the range $6-14 \%$ of the starting materials. In contrast, Ogner ${ }^{3}$ and Spiteller ${ }^{4}$ obtained yields of only $0.12-0.38 \%$ of these acids. In a careful quantitative study using permanganate oxidation, $\mathrm{H}$. A. Anderson of this institute (personal communication) has obtained a yield of $1.63 \%$ from a podzol Bh fulvic acid (Contech), similar to the Armadale preparation intensively studied by Schnitzer and coworkers. This yield does not greatly exceed that given by polymaleic acid in the same conditions $(0.8 \%)$.

Following the suggestion ${ }^{2}$ that ${ }^{13} \mathrm{C}$ NMR spectra could be used to estimate the amounts of benzene and hydroxybenzene polycarboxylic acids in the unfractionated oxidation products of fulvic acids, we have applied this technique to the products of peracetic acid oxidation. The results showed clearly that benzene polycarboxylic acids cannot be present in the amounts reported by Schnitzer and Skinner ${ }^{5}$.

In the absence of confirmation from other laboratories, the high yields of aromatic degradation products reported by Schnitzer and co-workers can carry no weight. We can only speculate on the reasons for these anomalously high yields.

The Macaulay Institute

V. C. FARMER

for Soil Research,

Craigiebuckler,

Aberdeen AB9 2QJ, UK

1. Preston, C. M. \& Schnitzer, M. J. Soil Sci. Soc. Am. 48, 305-311 (1984).

2. Farmer, V. C. \& Pisaniello, D. L. Nature 313, 474-475 (1985).

3. Ogner, G. Acta chem. scand. 27, 1601-1612 (1973).

4. Spiteller, M. Z. Pfl-Ernähr. Düng. Bodenk. 144, 472-485 (1981).

5. Schnitzer, M. \& Skinner, S. I. M. Can. J. Chem. 52, 1072$1080(1974)$

\section{Matters Arising}

Matters Arising is meant as a vehicle for comment and discussion about papers that appear in Nature. The originator of a Matters Arising contribution should initially send his manuscript to the author of the original paper and both parties should, wherever possible, agree on what is to be submitted. Neither contribution nor reply (if one is necessary) should be longer than 500 words and the briefest of replies, to the effect that a point is taken, should be considered. 